Canadian Food Studies

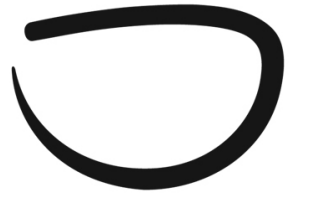

La Revue canadienne des études sur l'alimentation

\title{
Editorial
}

\section{Special issue on Indigenous Food}

\author{
Ellen Desjardins*
}

In the spring of 2016, I had a conversation with Dr. Kelly Skinner at the University of Waterloo which led to the mutual decision that we work towards a special issue of Canadian Food Studies on Indigenous Food. She was well connected with Canadian researchers, writers, activists, and artists on this topic, and felt that there was a plethora of potentially publishable material for such an issue. From the journal's perspective, an Indigenous focus would embody important and relevant aspects of food culture, politics, knowledge, history, world views, and practices that should be featured and honoured in a special issue.

For the Canadian Food Studies journal we have, from the beginning, emphasized our commitment to diversity of expression that can broadly range from original research to narratives to audio-visual works. Our aim is to build a body of voices, knowledges, and other materials that represents the community, academic, and individual contexts of food studies.

Dr. Skinner brought together a group of co-guest editors, all named in their editorial in this issue. The call for papers began with:

Grassroots activism by individuals and organizations like Leesee Papatsie and Feeding My Family has brought national and international attention to the challenges facing many Indigenous communities in regards to the high cost of food in the Far North. While extremely important, the current struggles faced by Inuit communities in northern Canada are only one piece of the story. The histories of Indigenous foodways and practices are vast and traverse multiple geographies and spaces (urban and rural, northern and southern, land and water, etc). Indigenous foodways include diverse worldviews and epistemologies; incorporate different land management activities/strategies; feature the many patterns and practices of survivance, resistance, and resurgence; combine Indigenous and Western food systems and practices; and 
encompass the imposition of colonial and corporate policy and governmentality.

The resulting submissions carried forth and expanded upon these ideas and more. For this we thank the authors and the guest editors. We hope you enjoy and benefit from the collective contributions in this special issue.

The editorial team appreciates the continued collaboration with the CAFS Journal Governance Committee, established in June 2016: Rebecca Schiff, Jennifer Brady, and Kristin Lowitt. We thank the University of Waterloo for providing our OJS online platform, which has been improved just prior to the release of this issue.

\section{Editorial Team}

Ellen Desjardins, PhD - Editor

Wesley Tourangeau, PhD - Managing and Associate Editor

Natalie Doonan, PhD - Associate Editor

Alyson Holland, PhD - Associate Editor

Jennifer Sumner, PhD - Associate Editor

Phil Mount, PhD - Associate Editor

David Szanto, PhD - Associate Editor 